\title{
To What Extent Can Existing Research Help Project Climate Change Impacts on Biodiversity in Aquatic Environments? A Review of Methodological Approaches
}

\author{
Anders Forsman ${ }^{1, *}$, Hanna Berggren ${ }^{1}$, Mats Åström ${ }^{2}$ and Per Larsson ${ }^{1}$ \\ 1 Center for Ecology and Evolution in Microbial Model Systems, EEMiS, Department of Biology and \\ Environmental Science, Linnaeus University, SE-391 82 Kalmar, Sweden; hanna.berggren@lnu.se (H.B.); \\ per.larsson@lnu.se (P.L.) \\ 2 Department of Biology and Environmental Science, Linnaeus University, SE-391 82 Kalmar, Sweden; \\ mats.astrom@lnu.se \\ * Correspondence: anders.forsman@lnu.se; Tel.: +44-480-44-61-73
}

Academic Editor: Kerstin Johannesson

Received: 14 September 2016; Accepted: 3 November 2016; Published: 10 November 2016

\begin{abstract}
It is broadly accepted that continued global warming will pose a major threat to biodiversity in the 21st century. But how reliable are current projections regarding consequences of future climate change for biodiversity? To address this issue, we review the methodological approaches in published studies of how life in marine and freshwater environments responds to temperature shifts. We analyze and compare observational field surveys and experiments performed either in the laboratory or under natural conditions in the wild, the type of response variables considered, the number of species investigated, study duration, and the nature and magnitude of experimental temperature manipulations. The observed patterns indicate that, due to limitations of study design, ecological and evolutionary responses of individuals, populations, species, and ecosystems to temperature change were in many cases difficult to establish, and causal mechanism(s) often remained ambiguous. We also discovered that the thermal challenge in experimental studies was 10,000 times more severe than reconstructed estimates of past and projections of future warming of the oceans, and that temperature manipulations also tended to increase in magnitude in more recent studies. These findings raise some concerns regarding the extent to which existing research can increase our understanding of how higher temperatures associated with climate change will affect life in aquatic environments. In view of our review findings, we discuss the trade-off between realism and methodological tractability. We also propose a series of suggestions and directions towards developing a scientific agenda for improving the validity and inference space of future research efforts.
\end{abstract}

Keywords: climate change; global warming; biological diversity; temperature manipulation experiments; thermal challenge

\section{Introduction}

Climate change is occurring, the atmosphere and oceans have warmed, the amounts of snow and ice have diminished, and the sea level has risen [1,2]. Models prognosticate that greenhouse gas concentrations will continue to rise, and that average air, surface and water temperature will increase as a result [1]. Accordingly, there is much concern about, and a growing demand for accurate projections of how climate change will impact biological diversity, global ecosystems, and the humans who depend on them [3-8]. Temperature is a key driver of organism function and ecosystem processes, and projected global warming will therefore affect biodiversity. There is an increasing need for research that 
provides answers to how species and communities respond to temperature shifts. Previous reviews and investigations into effects of temperature change on biodiversity have focussed on various types of responses, such as distribution range shifts [9-12], seasonal timing of reproductive activities [13,14], genetic adaptation [15], species survival [16,17], and biotic interactions [10,14,18]. Our present goal is not to summarize existing evidence for biodiversity responses to climate change by synthesizing results and estimating average effect sizes based on the findings in past research. Here, we instead explore whether research published within the context of climate change has been conducted in ways such that the results can inform about the consequences for biodiversity of water temperature increments associated with global warming. To this end, we perform a literature search and review empirical studies, analyze and describe general patterns in published biodiversity research with regard to methodological approaches-with particular focus on experimental studies-and then discuss the patterns in relation to reconstructions of past and prognostications of future rates and magnitudes of climate change. Next, we discuss the trade-off and balance between realism and methodological tractability, and provide an assessment of where there is a need for increased focus and shifts in research approaches. Finally, we offer suggestions and directions towards developing a scientific agenda for improving the validity and inference space of future research efforts concerning how climate change may affect biodiversity in aquatic environments.
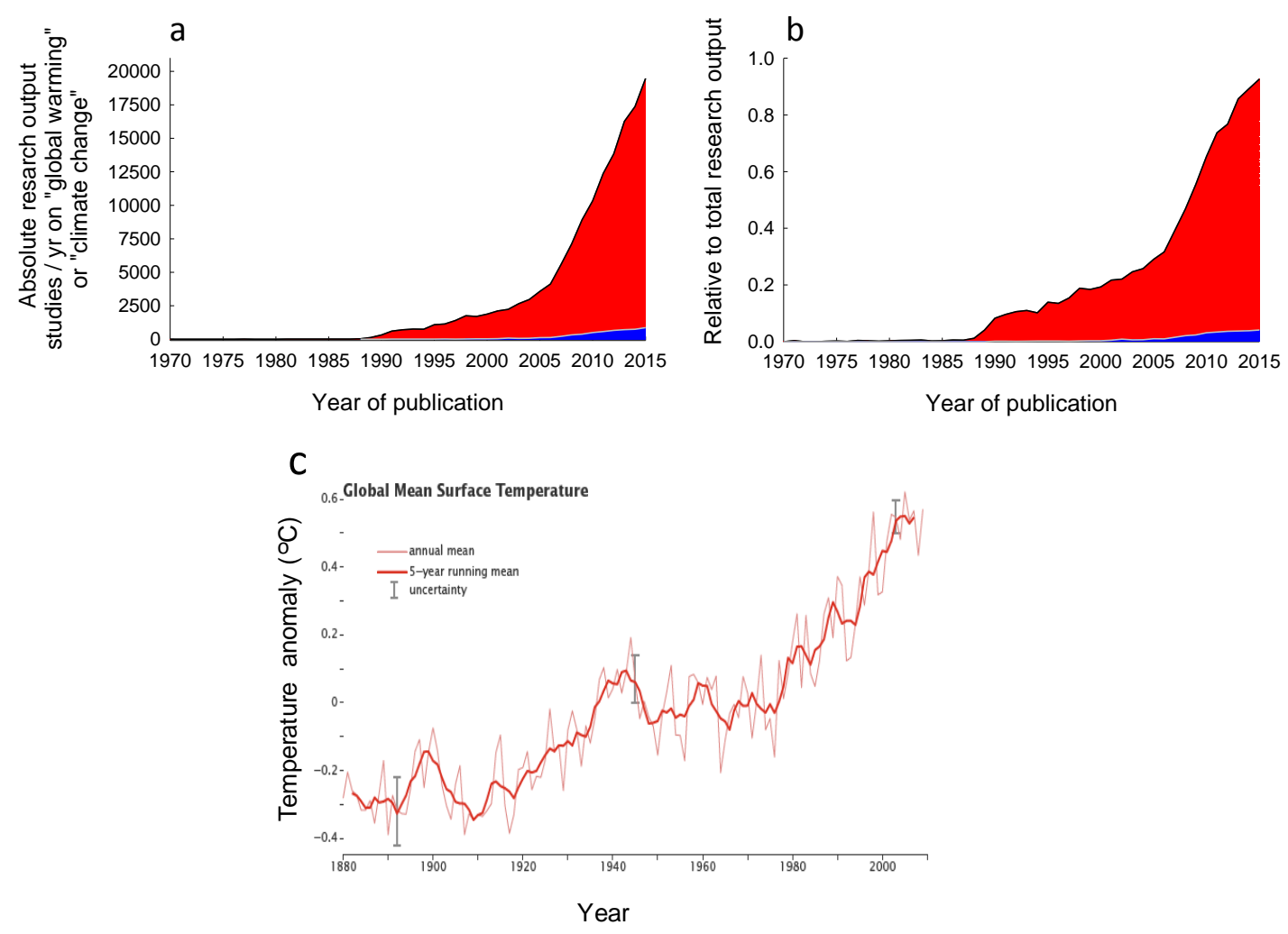

Figure 1. Trends in research output on global warming and past change in global mean surface temperature. (a) Absolute research output measured as number of publications on global warming published per year up to December 2015. Figure is based on data extracted from a topic search for "climate change" or "global warming" conducted 27 October 2016, from ISI Web of Science. The literature search yielded 141,501 papers, pooled across scientific disciplines, published between 1974 and December 2015 (indicated in red). Of these, 5740 studies concerned global warming and climate change within marine and freshwater environments (indicated in blue); (b) Relative research output on global warming expressed as percentage of total research output summed across all scientific disciplines; (c) Global warming as indicated by the rapid increase in Earth's average surface temperature over the past century (obtained from NASA's Earth Observatory [19]). 
The number of published articles on climate change and global warming is huge. Scientific output has increased exponentially with time, from less than 10 papers per year prior to 1980 to nearly 20,000 papers per year in 2015 (Figure 1a). The rapidly increasing output on global warming is evident also when expressed as a percentage of total research output summed across all scientific disciplines (Figure 1b). We focus our review on methodological approaches in studies of marine or freshwater environments. Due to the buffering effect of water, the temperature changes of water bodies occur at lower rates and magnitudes compared with terrestrial environments [1], although this buffering effect should be reduced in smaller and shallower water bodies. Due to limited potential for temperature regulation, organisms in aquatic environments have body temperatures that generally conform more closely to surrounding temperatures than do those of organisms in terrestrial systems. Additionally, the majority of animal life forms in aquatic environments are poikilotherms. Temperature shifts may therefore have more profound effects on community processes, and causal links between environmental temperature and organismal performance may be more readily studied and demonstrated in aquatic than in terrestrial systems.

\section{Materials and Methods}

\subsection{Protocol for Literature Search and Extraction of Data}

Our review is based on studies identified in a Web of Science (Science Citation Index expanded 1943-present) topic (Title, Abstract, or Keywords) search for "climate change" or "global warming" within the subject area "Marine and freshwater biology". The search was conducted on 2 February 2012, and yielded 2737 studies published up to December 2011. To find studies concerning any aspect(s) of biodiversity, studies were initially selected by Title, but if there was any doubt, the Abstract was acquired and judged. This yielded 746 studies. Of these, 463 had "climate change" or "global warming" in the Title. Studies were classified with regard to the following categories: Observational field survey; Experiment in the field; Experiment in the laboratory; Experiments in both field and laboratory; Model or simulation; or Review, and publication year.

Observational and experimental studies were classified with regard to the response considered: Community composition; Range shifts; Reproductive life-history; Survival (of individuals); Physiology; Growth, development or morphology; Behaviour; Extinction (local); Adaptation; or Several (if more than one of the previous types), the number and identity of species investigated, and study duration. Observational studies typically were based on field surveys, spatial comparisons along latitudinal gradients or depth transects, time series data, comparisons with historical data, correlations with temperature shifts associated with North Pacific or North Atlantic Oscillation Index, or on "natural experiments" based on changes co-occurring with unusual events such as El Niño or years with extreme weather conditions.

Experimental studies were also classified with regard to environmental setting (Laboratory or semi-natural conditions (e.g., mesocosms); or Field conditions), and type (constant, gradually changing, or fluctuating) and magnitude of temperature manipulation. Magnitude was estimated as the difference between two treatments, the difference between an experimental treatment and a control, or the change in temperature over time. If three or more treatment levels were used, the mean difference between treatments was used (e.g., for treatments 10,15 and $20^{\circ} \mathrm{C}$, we entered the value $5^{\circ} \mathrm{C}$ ).

\subsection{Estimating Thermal Challenge}

For experimental studies, we estimated harshness of the thermal challenge by dividing the magnitude of the temperature manipulation with study duration, expressed as ${ }^{\circ} \mathrm{C} \times$ year $^{-1}$. The result was compared with the rate of past climate change as estimated from the globally averaged combined land and ocean surface temperature data as calculated by a linear trend, showing a warming of $0.85{ }^{\circ} \mathrm{C}$, over the period 1880 to 2012 [1] (Figure 1c), and with the upper and lower bound of projections of future global ocean warming as calculated based on best estimates of ocean warming in the top one 
hundred meters of about $0.6{ }^{\circ} \mathrm{C}$ to $2.0^{\circ} \mathrm{C}$ by the end of the 21st century [1]. Estimated future ocean warming is lower, about $0.3^{\circ} \mathrm{C}$ to $0.6^{\circ} \mathrm{C}$, at a depth of about $1000 \mathrm{~m}$ [1].

Information on the duration of experiment and the magnitude of temperature manipulation was not available in all studies, and some studies provided information on one but not both of these variables (see $n$-values in legends to Figures $3-5$ ). Sample sizes therefore vary among the different comparisons reported below. However, it is unlikely that this should result in a systematic bias or influence the overall results or conclusions.

\section{Review Findings and Discussion}

\subsection{Frequency of Observational and Experimental Studies in the Literature Search}

Most studies identified by our literature search report on observational and correlative approaches based on different types of field surveys (spatial and temporal comparisons) that do not allow for identification of several causal co-varying biotic and abiotic factors, with possible interactive effects (Figure 2a). Establishing causal links between temperature change and biodiversity shifts is challenging, if not impossible, because of the complexity of natural systems, where populations are distributed patchily over heterogeneous environments, subject to a range of environmental conditions and interacting with other species. Two of the main virtues of experimental approaches in ecological research are to reduce the contribution to variation in the response variable of uncontrolled environmental factors (i.e., noise) that may obscure true effects, and identify the underlying driving mechanism(s) [20-22]. Firm demonstrations that temperature shifts influence performance of individuals, affect the ecological success of populations and species, and that they impact on the functioning of communities and ecosystems would therefore ultimately require experimental manipulations and replication $[7,22]$. About $40 \%$ of the reviewed studies fell within this category and report on comparisons between experimentally manipulated temperature treatments, with the remaining $60 \%$ of studies relying instead on observational approaches (Figure 2a).
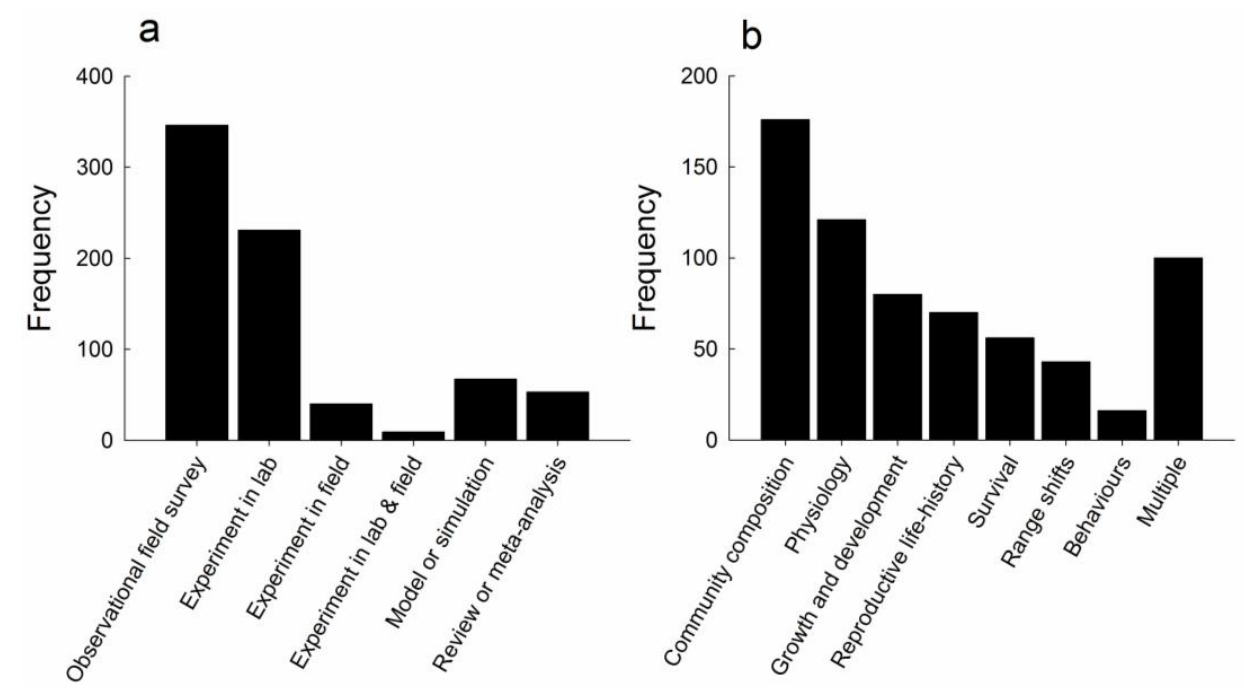

Figure 2. Methodological approaches and types of response variables used in observational and experimental studies of climate change effects on biodiversity in marine and freshwater environments. (a) Frequency distribution of methodological approaches; (b) Frequency distribution of types of response variables are shown for observational and experimental studies only. Multiple indicates that more than one type of response variable was used within a single study. Survival indicates studies that investigated effects on survival of individuals, not species or populations. Community patterns include response variables in the form of e.g., species composition. Figures are based on data for 746 (a, left panel) and 662 (b, right panel) studies. 


\subsection{Characteristics of Experimental Studies}

Of the experimental studies, most (83\%) were conducted under controlled laboratory conditions, and only a minority (3\%) used a combination of field and laboratory experiments (Figure 2a). To forecast the consequences of climate change, interfacing processes at different scales in space, time, and ecological organization must be taken into consideration $[7,23]$. It is reasonable to hypothesize that a larger fraction of the multifarious pathways and mechanisms by which temperature, and other factors, may affect fitness of individuals, populations and species [14,24-26] are operative under complex natural conditions that encompass a broader array of ecological interactions than in simpler, standardized settings. The effects seen in manipulation studies conducted under semi-natural or laboratory conditions may therefore differ and sometimes be weaker, compared with experiments conducted in the wild $[27,28]$. Despite this, most ecological studies generally use single-species approaches [29]. A similar pattern is evident among the studies of biodiversity effects of temperature change; the majority (60\%) of investigations studied single species; $18 \%$ studied two different species; and in $22 \%$ of the investigations, three or more focal species were studied. Investigating how different species are affected by temperature change can provide valuable knowledge. However, the performance of species depends on interactions with other individuals belonging to the same species, as well as on interactions with different species that may represent food, competitors, predators, herbivores, pathogens or parasites. Linkage density of interactions and connectance among species within natural food webs may be immensely more complex than anticipated based on direct observations of pairwise encounters [30,31]. Effects of climate change that may be mediated by species interactions, changes in community composition, cascading effects and ecosystem processes $[14,26,29]$ have therefore likely gone undetected in the majority of the experiments.

\subsection{Response Variables Investigated}

The consequences of climate change and associated temperature shifts for species and populations are simple in principle: they can respond by range shifts; adaptation via evolutionary (genetically based) change or phenotypic plasticity; or become extinct. These responses may in turn impact higher level processes, community composition, and ecosystem functioning. A minority (30\%) of the studies reviewed here specifically addressed one of the three ultimate species-level consequences of climate change, viz. range shifts, whereas no study addressed extinction or adaptation (Figure 2b). Approximately one fifth (22\%) of studies investigated reproductive life-history traits or individual survival which can ultimately influence extinction risk, and one tenth $(8 \%)$ concerned range shifts (Figure 2b). None of the studies reviewed here provided evidence for genetic adaptation to climate change-as discussed in greater detail elsewhere [15].

\subsection{Duration of Studies}

The experimental studies were of short duration and typically lasted for two weeks (median 14 days, range $1 \mathrm{~h}-5$ years.) (Figure $3 \mathrm{a}$ ). It has long been recognized that the impacts of changing environments depend on the spatiotemporal scale of environmental heterogeneity relative to the generation time and dispersal capacity of the organism [32]. The most common focal species were bony fish, followed by corals, and phytoplankton. In many cases, study duration is therefore insufficient to pick up important responses such as population extirpation, species extinctions $[9,11]$ and evolutionary change (adaptation) that typically require tens of generations or more to manifest [15]. By comparison, observational field studies based on data collected at different locations or from the same location(s) on different occasions were of much longer duration, typically spanning over 13 years (range 9 days-230 years.) (Figure 3b). Yet, the approach and spatiotemporal scale of most field surveys is such that behavioural responses to climate change in the form of shifts in the timing of seasonal activities [13,14], individual movements and species range shifts $[9,11,12]$ likely have gone undetected in many studies. Interpretation and comparisons of results regarding range shifts across studies is 
complicated further by the finding in a recent meta-analysis of studies of terrestrial organisms that rates of range shifts depend on both time period and study duration [33]. Given that estimated rates of range shifts increase with decreasing study duration [33], there is a risk that shorter studies overestimate climate change impacts.

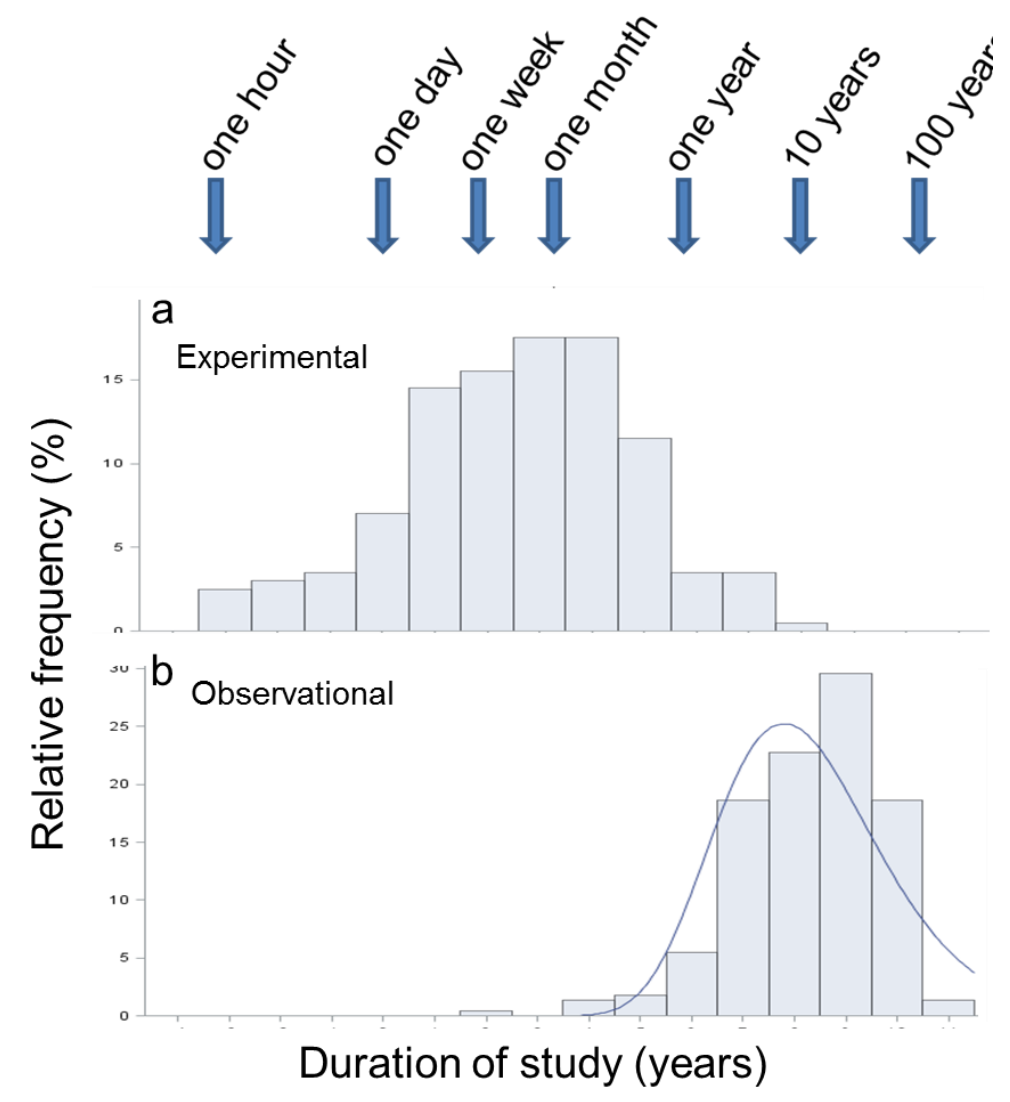

Figure 3. Frequency distribution of temporal duration of (a) experimental and (b) observational studies of climate change impacts on biodiversity in marine and freshwater environments. For observational studies based on comparisons of current with historical data, time elapsed between sampling occasions was used as a measure of study duration. Duration of study is plotted on a logarithmic scale. Figure is based on data for 207 experimental and 220 observational studies.

\subsection{Nature and Magnitude of Experimental Temperature Manipulations}

The degree to which manipulation studies can inform about responses to future climate change depends in part on whether the experimental conditions and the magnitude of temperature manipulations resemble the thermal challenge associated with warming in the natural environment. According to the Fifth Intergovernmental Panel on Climate Change (IPCC) report, the globally averaged combined land and ocean surface temperature data as calculated by a linear trend, show a warming of $0.85{ }^{\circ} \mathrm{C}$ over the period 1880 to 2012 [1]. On a global scale, ocean warming is highest near the surface, and the upper $75 \mathrm{~m}$ warmed by $0.11^{\circ} \mathrm{C}$ per decade over the period 1971 to 2010 [1]. About $75 \%$ of the biodiversity studies reviewed here used an approach based on comparisons between two or more different but constant temperature treatments. In nearly all (98\%) experiments, the difference between temperature treatments (median $=4{ }^{\circ} \mathrm{C}$, range $=1$ to $22^{\circ} \mathrm{C}$ ) was larger than $1{ }^{\circ} \mathrm{C}$, and thus exceeded the increase in the global mean surface temperature documented during the past 100 years. (Figure 4). The thermal challenge to which study organisms were exposed in the experimental studies also exceeded by far the boundaries of climate change projections for the future (see below and Figure 5). Using exaggerated experimental treatment levels and simplified settings during 
the developing stages of new research areas is one way to generate preliminary results that can help design better informed investigations. However, there is no indication that the more recently published experiments use temperature manipulations of lower magnitude; instead there is a weak but statistically significant trend that the magnitude of temperature manipulations has increased over time ( $r_{\mathrm{s}}=0.16, P=0.019, n=216$; least-squares linear regression of $\log$ (temperature difference) on year of publication, $F_{1,214}=4.26, P=0.040, R^{2}=0.020$, slope coefficient \pm s.e. $=0.021 \pm 0.0104$ ).

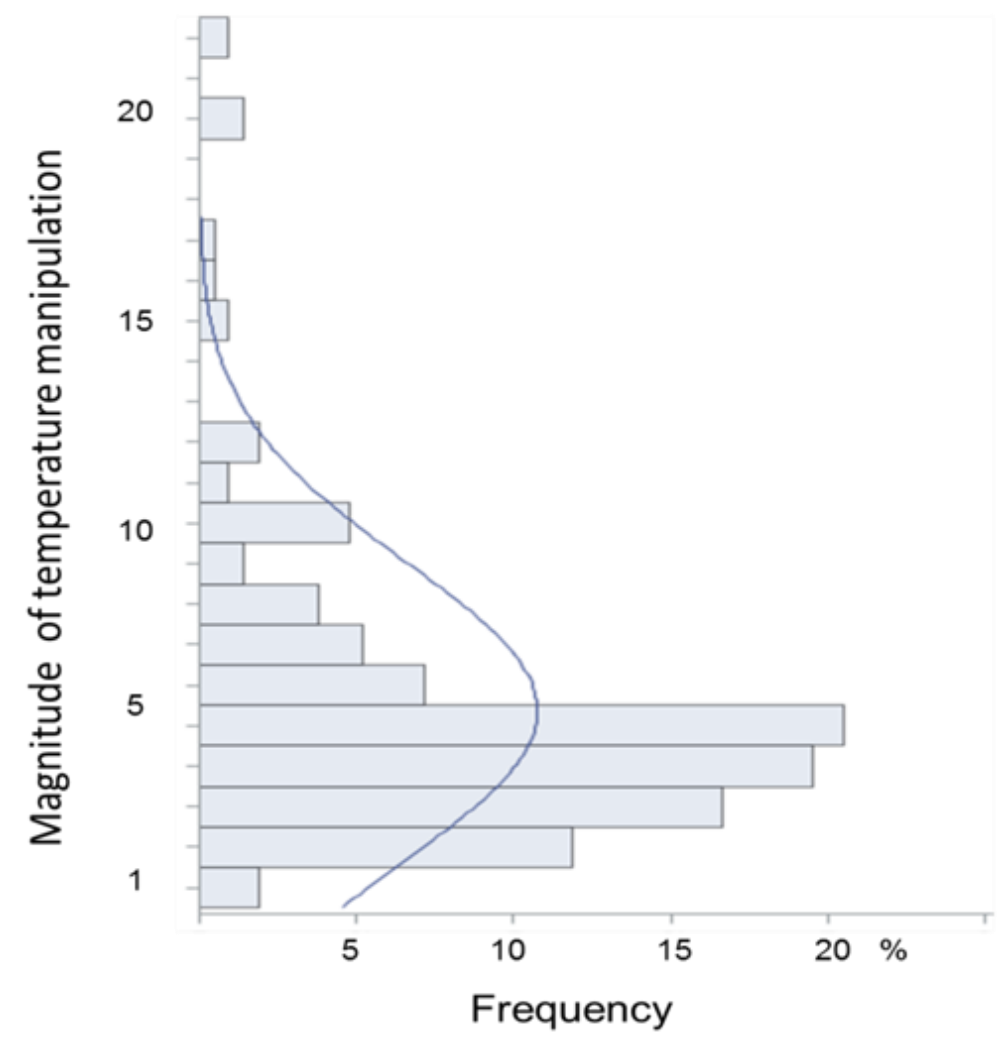

Figure 4. Magnitude of temperature manipulations in experimental studies of climate change impacts on biodiversity in freshwater and marine environments. Relative frequency distribution of the magnitude of temperature manipulations (based on data for 216 experimental studies). The magnitude of the temperature manipulation was calculated as the average temperature difference between treatments (for studies with fixed treatments) or as the change in temperature over time (for studies that used gradually increasing temperature treatments).

About $17 \%$ of the experimental studies used an approach in which temperature fluctuated around a stable mean. This was achieved, for instance, by supplying aquaria with naturally fluctuating water that originated from the sea $(10 \%)$, or by artificially generating variable temperatures $(7 \%)$. Oscillating environments may impose a greater challenge, and have different outcomes than sudden transitions followed by new equilibria ("fixed states"). Selection pressures associated with occasional brief episodes of extreme temperatures can be very different from those that operate during normal conditions, and drastically influence population fitness. Few experimental studies (5\%) used a fluctuating and gradually increasing temperature treatment that qualitatively resembled to some extent the change that has occurred during the past 100 years [1] (Figure 1c). However, the thermal challenge severity (expressed as ${ }^{\circ} \mathrm{C} \times$ year ${ }^{-1}$ ) in the experimental studies exceeded by several orders of magnitude (median: 10,000) the rate of water temperature increase projected for the oceans for the century to come [1] (Figure 5). Estimated future ocean warming is not uniform across the globe [1], but the magnitudes of such regional differences do not match the discrepancy indicated in Figure 5. 


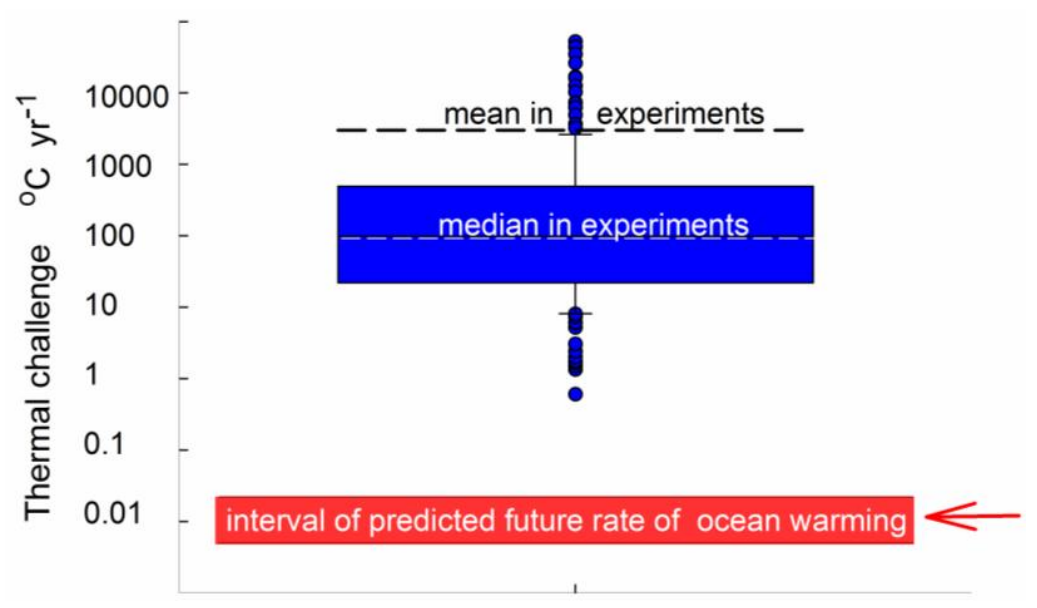

Figure 5. Thermal challenge severity in experimental studies of climate change impact on biodiversity in marine and freshwater environments in relation to reconstructions of past land and ocean global warming and prognosticated future global ocean warming. Thermal challenge severity (in ${ }^{\circ} \mathrm{C} \times$ year ${ }^{-1}$ ) was calculated as the ratio of the magnitude of the difference in temperature between treatments (for studies with fixed treatments) or change in temperature over time (for studies with a gradually changing temperature treatment) and study duration in years. The hatched line above the box indicates the mean, the solid line within the box indicates the median, the boundaries of the box indicate 25th and 75th percentiles, whiskers below and above indicate 10th and 90th percentiles, and dots indicate outlying observations among the experimental studies. Box plot is based on data for 194 experimental studies. The red arrow to the right indicates the rate of past climate change, estimated from the globally averaged combined land and ocean surface temperature data as calculated by a linear trend, show a warming of 0.85 ( 0.65 to 1.06$){ }^{\circ} \mathrm{C}$, over the period 1880 to 2012 [1]. The red box indicates the upper and lower bound of the rate of future global ocean warming, as calculated based on best estimates of ocean warming in the top one hundred meters of about $0.6{ }^{\circ} \mathrm{C}$ to $2.0^{\circ} \mathrm{C}$ by the end of the 21st century [1]. Estimated future ocean warming is lower, about $0.3^{\circ} \mathrm{C}$ to $0.6^{\circ} \mathrm{C}$, at a depth of about $1000 \mathrm{~m}$ [1].

The combination of temperature manipulations and durations of the reviewed experiments can contribute important knowledge and understanding of how individuals, species and communities are affected by temperature changes at scales associated with variable weather conditions, seasonality, or episodic "pulse" events of regional warming of ocean waters, such as those associated with El Niño Southern Oscillation (ENSO) cycles or El Niño events. However, it seems questionable whether and how the nature and magnitude of experimental temperature manipulation regimes used in most studies allow for inferences about future and more long-term climate change impacts on biodiversity.

It might be argued that the reviewed experimental studies on which the above analysis on thermal challenge was based were not designed to investigate consequences of climate change, and that our conclusion and critique regarding experimental design and thermal challenge is therefore unfair. However, as explained in Materials and Methods (Section 2.1), our topic literature search was designed to target only those publications in which "global warming" or "climate change" was included in the Title, Abstract, Keywords or a combination of these. In more than half (463 of 746) of the reviewed studies, one of our search terms was included in the Title, indicating that the author(s) considered the work highly relevant within a climate change context. In the majority (167) of the 216 experiments for which information was available on both magnitude of temperature manipulation and study duration, climate change or global warming was explicitly stated either in the aims or conclusions (or both) in the Abstract. In an additional 25 experimental studies, the authors alluded to elevated sea temperatures, climate effects, or warming temperatures in the Abstract and included our search terms in the title or keywords. In the remaining 18 experiments, the search terms were not mentioned in the Abstract but included in the Title. This means that it was not us but the authors themselves that placed 
the aim/question/hypothesis/implication of the studies included in this methods-review within the framework of climate change.

There were no differences between experimental studies that did not, and experimental studies that explicitly did, include climate change or global warming in aims or conclusions statements in the Abstract regarding the magnitude of the difference between temperature treatments (Median Two-Sample Test, $Z=0.40, P=0.69)$, study duration $(Z=1.00, P=0.32)$, or thermal challenge severity $(Z=0.91, P=0.36)$. This argues against the interpretation that the nature of the temperature manipulations was different depending on the degree to which authors linked their studies to climate change issues.

\subsection{General Discussion and Overall Assessment of Approaches Used in the Reviewed Studies}

Warming of the planet will have many side effects, including reduction of the ice cover and permafrost, changes in ocean currents and precipitation patterns, and increased ocean acidification, storm frequency, turbidity and floods [1,2]. Together with continuously changing and expanding human land use they will impact biodiversity. There is little doubt that the methodological approaches used in the studies included in this review can provide important insights into how temperature influences performance of individual organisms and ecosystems in marine and freshwater environments, and further our understanding of how biodiversity responds to spatially heterogeneous environments, changing weather conditions, and seasonality. However, the degree to which the studies also provide information that allows for reliable and realistic projections regarding biodiversity consequences in aquatic ecosystems of increased water temperatures associated with future climate change remains uncertain. Due to the potential problems associated with study design discussed in the preceding sections, it is difficult merely to discern what we currently do and do not know about marine and freshwater ecological responses to long-term global warming. On a more positive note, our work offers important realizations and guidelines for research to come.

To investigate and project how biodiversity will change as a result of overall small temperature increments on time scales that in the perspective of normal scientific studies are very long is hard $[6,7]$. Improving the reliability of future climate change consequence models requires an agenda that aims to more truthfully resemble future changes (albeit uncertain) and processes that are operative under natural situations in the wild. More accurate projections of climate change consequences also requires data from long-term (across generations), replicated experiments with appropriate controls, conducted at spatiotemporal scales relevant for the species and community under investigation, and realistic (oscillating and gradually increasing at a slow rate) temperature manipulation regimes. Single-species and single-factor experiments can provide valuable insights and knowledge, but are not sufficient to investigate biodiversity responses to climate change, there is a need for multifactorial experiments that assess the combined additive and interactive effects of temperature and other environmental conditions $[7,22,34]$.

\subsection{Finding the Balance between Realism and Methodological Tractability}

There is necessarily a trade-off between "real-world" complexity and tractability of manipulation experiments. The simplification process involved in experimental design is fundamental to how we gain knowledge, and it defines inference space. There will always be room for disagreements about what is an acceptable realism gap, and there will always be room for increased realism, for example by further increasing species complexity or reducing temperature challenge. Therefore, it is of course relevant to ask when enough is enough.

It is reasonable to hypothesize that the nature of the relationship linking quality of results (or inference space or projective power) to the level of experimental realism is non-linear and follows the law of diminishing returns, such that efforts toward increasing realism may initially be very rewarding while generating little additional benefit beyond a certain level of realism increment. Has research investigating climate change impacts on biodiversity in aquatic environments yet approached the 
asymptote? Based merely on the distribution of the reviewed studies across methodological categories outlined above, a subjective answer would be no. However, it would be possible (but difficult) to objectively investigate this issue by conducting (or comparing) a series of experiments with different levels of realism (with regard to species complexity, nature and severity of temperature challenge, or study duration) and examine whether and how outcomes and conclusions change depending on realism or degree of complexity [27,34,35]. Results of a recent meta-analysis [36] show that experimental warming reduces community species richness in marine but not in freshwater systems, that there were no impacts on evenness in aquatic systems, that intensity and duration of experimental warming did not explain variation in responses among studies, and that biodiversity effects depended on local species composition.

\section{Directions for the Future}

\subsection{Steps towards Increased Realism}

Theoretical models, simulations, observational studies and manipulation experiments must make simplifications in order to be tractable. As we have seen, simplifications come in the form of excluding complex interactions of which there is insufficient knowledge and data; conducting experiments in the laboratory to control for "noise" that complicates interpretation of experiments conducted in the field; conducting experiments on plots that are of a practical size and over time frames that are realistic to maintain; and using experimental temperature manipulation regimes that are practical and likely to generate detectable effects. Such simplifications are understandable and often justified. However, some steps towards increased realism and expanded inference space are possible even within the constraints set by practical limitations, whereas tackling more ambitious research goals also requires that actions are taken to overcome certain constraints to study design.

\subsubsection{Assess and Identify Causes of Heterogeneity of Biodiversity Responses to Climate Change}

Past and future rates of warming vary across the globe [1]. Coordinated efforts could help evaluate whether responses to common manipulations (of e.g., temperature or salinity) depend on ecosystem type, species composition, or the evolutionary history of the focal species. This is an important task. If shared responses are common, this would allow for broad generalizations and transfer of knowledge. If, on the other hand, responses are heterogeneous and context dependent, this might help identify environmental factors and species characteristics that potentially mould the ways biodiversity is influenced by climate change. Comparisons of observational studies carried out in different areas can potentially generate similar insights. For instance, results from a meta-analysis of studies of terrestrial organisms indicate that rates of poleward range margin shifts vary among studies and decrease with increasing mid-latitude [33].

4.1.2. Target those Response Variables that are likely to be of Importance for Biodiversity Responses to Climate Change

Only one third of observational and experimental studies reviewed here specifically investigated effects of temperature on reproductive life-history, survival or range shifts, and no study addressed or demonstrated evolution. To select different or include additional response variables should be feasible within the frameworks of single projects and the potential benefits would in many cases likely outweigh the costs associated with any increase in sampling efforts. If more researchers include several response variables in their studies, this will also provide for larger sample sizes and increased power in future comparative investigations and meta-analysis.

\subsubsection{Use Multi-Species Approaches}

Only one fifth of the studies included in this review included three or more focal species. Even single-species studies can provide important contributions for the understanding of climate 
change impacts on biodiversity, and help disentangle results from more complex experiments and settings. However, the performance and ecological success of individuals, species and communities is defined by interactions of the abiotic environment and by complex interactions between individuals belonging to the same or to different species. Rosenblatt and Schmitz [34] synthesized literature on the interactive effects of multiple climate change variables (e.g., temperature, precipitation, $\mathrm{CO}_{2}, \mathrm{O}_{3}$, ultraviolet radiation) on trophic interactions. They report that the qualitative effect on response variables directly related to trophic interactions (such as feeding rate, weight gain, and population biomass) depend on whether climate change variables were manipulated alone or together. Furthermore, both response type and magnitude are highly context dependent, indicating that unanticipated emergent effects of climate change on ecosystems are likely to occur [34]. As suggested elsewhere [18], eco-evolutionary dynamics and the roles of direct and indirect multi-species interactions can be studied from an evolving meta-community perspective to obtain deeper insights into the complex issue of how abiotic factors and species interactions together and in an interdependent manner shape biodiversity responses to climate change [10,14,18,26,29].

Theoretical development has progressed faster than the accumulation of empirical tests of interactive responses to climate change [18]. In the wait of more experiments within the co-evolving species interaction framework, there is room also for researchers and groups not primarily interested in community ecology to improve the situation, maximize resources, enhance research capacity and generate added value. For instance, it is conceivable that a manipulation experiment originally designed by ecologists working on fish for studying how temperature influences hatching success of eggs, survival of larvae and growth of fry with only minor modifications to study design and sampling scheme can generate valuable information also on bacteria, zooplankton or phytoplankton.

\subsubsection{Use Temperature Regimes Better Suited for Making Inferences about Climate Change Effects} on Biodiversity

The median difference between experimental temperature treatments in the studies reviewed here was $4{ }^{\circ} \mathrm{C}$. During the planning stage, researchers may consider whether it would be appropriate and logistically feasible to increase the number of temperature treatment levels and reduce the magnitude of temperature intervals between treatments. Even if this comes at the cost of reduced replication within treatment levels, it allows for more accurate estimation of the shape of thermal performance curves and location of the thermal optima. About $75 \%$ of the studies included in this review used a fixed temperature manipulation. In future experiments, it should be considered whether fluctuating or gradually increasing temperature treatments would be equally or more suitable, and whether study duration could be increased to reduce the severity of the thermal challenge.

\subsection{Big Challenges Call for Ambitious Actions and Solutions}

The suggested changes in approach and modifications to study design necessary to improve realism and power of projections of climate change-induced effects on biodiversity are hard to implement given the time frames and budgets of research projects. However, collaborations in the form of large data set sharing (big data initiatives), development of robust metadata, networking technology, establishment of well-curated open data repositories can help scientists overcome limitations due to large data sets, and offer access to comprehensive data for reviews and comparative studies as in genetics, ecology and environmental research [37,38]. There are several examples of such approaches, such as The Tree of Life Web Project [39], The IUCN Red List of Threatened Species [40] (International Union for Conservation of Nature), and The International Nucleotide Sequence Database Collaboration (INSDC) [41]. For endeavours that require more resources than are typically available to individual scientists, groups or institutions, national or international consortia in which member organizations and individuals work towards common specified goals and objectives may offer fruitful avenues to progress. A case in point of direct relevance for the current discussion is the Intergovernmental Panel on Climate Change (IPCC), a scientific body which does not carry out original research nor monitor 
climate or related phenomena itself, but produces reports to which thousands of scientists and experts contribute and which are subject to approval by delegates from all participating governments [1]. A similar initiative is the Intergovernmental Science-Policy Platform on Biodiversity and Ecosystem Services (IPBES) [42], which helps coordinate the planning, execution and dissemination of research concerning the consequences of climate change for biodiversity.

Joint ventures, international collaboration and co-funding have enabled the acquisition and construction of large-scale infrastructure facilities for research and related activities in other contexts, for instance, the Svalbard Global Seed Vault [43]. By comparison, more modest, cheaper and technically less demanding facilities would suffice to tackle ambitious research questions within the framework of climate change impacts on biodiversity.

\subsection{Experimental Temperature Manipulation in the Wild}

Ultimately, there is a need for large-scale, long-term and replicated temperature experiments in the wild. Although logistically and financially challenging, it should be possible to experimentally elevate water temperatures in a series of natural ponds, small lakes or to create temperature gradients in coastal bays in the Sea. This would allow for cross sectional before versus after comparisons and generate valuable longitudinal time series data. Comparisons could be made with unmanipulated control areas. Temperature manipulation in the wild would offer valuable resources for a broad range of research questions pertaining to the effects of temperature change on the performance of individuals and species, community composition and interactions, and ecosystem functioning. Initiatives to such large-scale thermal elevation areas should ideally include on-site laboratory facilities and be accompanied by long-term funding for maintenance to secure consistent monitoring and sampling. Clearly there is a series of ethical issues to consider before such large-scale experiments are initiated.

Scientists can also monopolize on already existing warm water effluents, such as emission of heated cooling water from power plants (e.g., [44-49]). If information on base-line levels is available from surveys conducted before construction, the effects of the temperature increase can be evaluated based on comparisons with more current situations as estimated from monitoring programs of recipient areas [49]. Temperature elevations likely exceed those associated with global warming [1], but comparisons along gradients from the core and out towards less affected and control areas might help evaluate effects of different magnitudes of change in complex systems. Some organisms lend themselves to the study of adaptation to temperature change by means of historical reconstructions. For species with dormant eggs or seeds that accumulate in chronologically layered sediments, ancestral character states can be determined by cultivating individuals from the past [50]. Within the framework of resurrection ecology [51], evolution can potentially be assessed by rearing such eggs in temperature gradients and comparing their thermal tolerance and performance curves with those of extant populations in the recipient area.

\subsection{Ecologists and Evolutionary Biologists Must Rise to the Challenge}

The directions for future research outlined above, and other improvements to study design [7,52], together with the integration of information obtained from different systems and approaches [6], should yield a clearer, more realistic view, and strengthen the validity of future investigations into biodiversity and ecosystem responses to increased overall water temperatures associated with climate change. Compared with investigations into ecological responses, evolutionary biologists are faced with even greater challenges. There is little doubt that climate change will result in marked and widespread changes in selection pressures. However, it remains uncertain whether evolutionary responses can in general be sufficiently rapid to allow for genetically based adaptations to keep pace with the expected rates of environmental changes and shifting selection pressures brought about by climate change [53]. Predictions are complicated also because global warming can influence population sizes, patterns of gene flow, and the potential for hybridization-all of which might influence evolution. Clarifying the role of evolution is challenging also because it is difficult to separate genetic adaptations from 
non-genetic plasticity. Benefits from developmental plasticity and phenotypic flexibility for population persistence in the face of environmental change can be large [35,54], and plasticity and flexibility are relatively easy to detect compared with genetic changes [15]. While plasticity has potential to boost evolutionary adaptations, it can also reduce the evolutionary response to natural selection and thereby prevent genetic adaptation. Empirical studies of the relative roles of plasticity and evolutionary responses within the context of climate change are in high demand but challenging to perform [53]. Even less is known about how adaptations and evolutionary changes at the species level brought about by climate change will impact species interactions, community composition and ecosystem functioning. Global warming and its consequences are a major concern for us all. It is crucial that resources and facilities are obtained for tackling also more ambitious research goals, and meeting the demands for large-scale, long-term studies and experiments with greater realism. The future we are about to enter will likely be warmer, and it is our common obligation to ensure that it will also be enlightened.

Acknowledgments: The study was supported financially by Linnaeus University, by Nova (Nova Centre for University Studies, Research and Development, Oskarshamn, Sweden, project nr. 20-11-3) and by Swedish Nuclear Fuel and Waste Management Company (SKB). We thank P. Tibblin and two anonymous reviewers for comments on the manuscript.

Author Contributions: A.F., P.L., M.Å. and H.B. conceived and designed the study; H.B. performed the literature search; H.B. and A.F. extracted the data; A.F. and H.B. analyzed the data; A.F. wrote the first draft; H.B., P.L. and M.Å. contributed to the writing.

Conflicts of Interest: The authors declare no conflict of interest. The founding sponsors had no role in the design of the study; in the collection, analyses, or interpretation of data; in the writing of the manuscript, and in the decision to publish the results.

\section{References}

1. Intergovernmental Panel on Climate Change. Climate Change 2013: The Physical Science Basis. Contribution of Working Group I to the Fifth Assessment Report of the Intergovernmental Panel on Climate Change; Cambridge University Press: Cambridge, UK; New York, NY, USA, 2013; p. 1535.

2. Gleick, P.H.; Adams, R.M.; Amasino, R.M.; Anders, E.; Anderson, D.J.; Anderson, W.W.; Anselin, L.E.; Arroyo, M.K.; Asfaw, B.; Ayala, F.J.; et al. Climate change and the integrity of science. Science 2010, 328, 689-690. [CrossRef] [PubMed]

3. Botkin, D.B.; Saxe, H.; Araújo, M.B.; Betts, R.; Bradshaw, R.H.W.; Cedhagen, T.; Chesson, P.; Dawson, T.P.; Etterson, J.R.; Faith, D.P.; et al. Forecasting the effects of global warming on biodiversity. BioScience 2007, 57, 227-236. [CrossRef]

4. Tilman, D.; Fargione, J.; Wolff, B.; D'Antonio, C.; Dobson, A.P.; Howarth, R.; Schindler, D.; Schlesinger, W.H.; Simberloff, D.; Swackhamer, D. Forecasting agriculturally driven global environmental change. Science 2001, 292, 281-284. [CrossRef] [PubMed]

5. Ash, C.; Culotta, E.; Fahrenkamp-Uppenbrink, J.; Malakoff, D.; Smith, J.; Sugden, A.; Vignieri, S.N. Once and future climate change. Science 2013, 341, 472-473. [CrossRef] [PubMed]

6. Dawson, T.P.; Jackson, S.T.; House, J.I.; Prentice, I.C.; Mace, G.M. Beyond predictions: Biodiversity conservation in a changing climate. Science 2011, 332, 53-58. [CrossRef] [PubMed]

7. Shaver, G.R.; Canadell, J.; Chapin, F.S.; Gurevitch, J.; Harte, J.; Henry, G.; Ineson, P.; Jonasson, S.; Melillo, J.; Pitelka, L.; et al. Global warming and terrestrial ecosystems: A conceptual framework for analysis. BioScience 2000, 50, 871-882. [CrossRef]

8. Hsiang, S.M.; Burke, M.; Miguel, E. Quantifying the influence of climate on human conflict. Science 2013, 341. [CrossRef] [PubMed]

9. Thomas, C.D.; Franco, A.M.A.; Hill, J.K. Range retractions and extinctions in the face of climate warming. Trends Ecol. Evol. 2006, 21, 415-416. [CrossRef] [PubMed]

10. Walther, G.-R.; Post, E.; Convey, P.; Menzel, A.; Parmesan, C.; Beebee, T.J.C.; Fromentin, J.-M.; Hoegh-Guldberg, O.; Bairlein, F. Ecological responses to recent climate change. Nature 2002, 416, 389-395. [CrossRef] [PubMed] 
11. Devictor, V.; van Swaay, C.; Brereton, T.; Brotons, L.; Chamberlain, D.; Heliola, J.; Herrando, S.; Julliard, R.; Kuussaari, M.; Lindstrom, A.; et al. Differences in the climatic debts of birds and butterflies at a continental scale. Nat. Clim. Chang. 2012, 2, 121-124. [CrossRef]

12. Parmesan, C.; Ryrholm, N.; Stefanescu, C.; Hill, J.K.; Thomas, C.D.; Descimon, H.; Huntley, B.; Kaila, L.; Kullberg, J.; Tammaru, T.; et al. Poleward shifts in geographical ranges of butterfly species associated with regional warming. Nature 1999, 399, 579-583. [CrossRef]

13. Gill, J.A.; Alves, J.A.; Sutherland, W.J.; Appleton, G.F.; Potts, P.M.; Gunnarsson, T.G. Why is timing of bird migration advancing when individuals are not? Proc. R. Soc. B 2014, 281. [CrossRef] [PubMed]

14. Ovaskainen, O.; Skorokhodova, S.; Yakovleva, M.; Sukhov, A.; Kutenkov, A.; Kutenkova, N.; Shcherbakov, A.; Meyke, E.; del Mar Delgado, M. Community-level phenological response to climate change. Proc. Natl. Acad. Sci. USA 2013, 110, 13434-13439. [CrossRef] [PubMed]

15. Merilä, J.; Hendry, A.P. Climate change, adaptation, and phenotypic plasticity: The problem and the evidence. Evol. Appl. 2014, 7, 1-14. [CrossRef] [PubMed]

16. Lorenzen, E.D.; Nogues-Bravo, D.; Orlando, L.; Weinstock, J.; Binladen, J.; Marske, K.A.; Ugan, A.; Borregaard, M.K.; Gilbert, M.T.P.; Nielsen, R.; et al. Species-specific responses of late quaternary megafauna to climate and humans. Nature 2011, 479, 359-364. [CrossRef] [PubMed]

17. Thomas, C.D.; Cameron, A.; Green, R.E.; Bakkenes, M.; Beaumont, L.J.; Collingham, Y.C.; Erasmus, B.F.N.; de Siqueira, M.F.; Grainger, A.; Hannah, L.; et al. Extinction risk from climate change. Nature 2004, 427, 145-148. [CrossRef] [PubMed]

18. Urban, M.C.; de Meester, L.; Vellend, M.; Stoks, R.; Vanoverbeke, J. A crucial step toward realism: Responses to climate change from an evolving metacommunity perspective. Evol. Appl. 2012, 5, 154-167. [CrossRef] [PubMed]

19. NASA's Earth Observatory: Global Warming. Available online: http://earthobservatory.nasa.gov/Features/ GlobalWarming/page2.php (accessed on 11 November 2016).

20. Stewart, R.I.A.; Dossena, M.; Bohan, D.A.; Jeppesen, E.; Kordas, R.L.; Ledger, M.E.; Meerhoff, M.; Moss, B.; Mulder, C.; Shurin, J.B.; et al. Mesocosm experiments as a tool for ecological climate-change research. In Advances in Ecological Research; Guy, W., Eoin, J.O.G., Eds.; Academic Press: Cambridge, MA, USA, 2013; Volume 48, pp. 71-181.

21. Griffen, B.D.; Drake, J.M. A review of extinction in experimental populations. J. Anim. Ecol. 2008, 77, 1274-1287. [CrossRef] [PubMed]

22. Wu, Z.T.; Dijkstra, P.; Koch, G.W.; Penuelas, J.; Hungate, B.A. Responses of terrestrial ecosystems to temperature and precipitation change: A meta-analysis of experimental manipulation. Glob. Chang. Biol. 2011, 17, 927-942. [CrossRef]

23. Levin, S.A. The problem of pattern and scale in ecology: The robert h. Macarthur Award Lect. Ecol. 1992, 73, 1943-1967.

24. Wennersten, L.; Forsman, A. Population-level consequences of polymorphism, plasticity and randomized phenotype switching: A review of predictions. Biol. Rev. 2012, 87, 756-767. [CrossRef] [PubMed]

25. Hughes, A.R.; Inouye, B.D.; Johnson, M.T.J.; Underwood, N.; Vellend, M. Ecological consequences of genetic diversity. Ecol. Lett. 2008, 11, 609-623. [CrossRef] [PubMed]

26. Reusch, T.B.H.; Ehlers, A.; Hämmerli, A.; Worm, B. Ecosystem recovery after climatic extremes enhanced by genotypic diversity. Proc. Natl. Acad. Sci. USA 2005, 102, 2826-2831. [CrossRef] [PubMed]

27. Forsman, A. Effects of genotypic and phenotypic variation on establishment are important for conservation, invasion and infection biology. Proc. Natl. Acad. Sci. USA 2014, 111, 302-307. [CrossRef] [PubMed]

28. Skelly, D.K. Experimental venue and estimation of interaction strength. Ecology 2002, 83, $2097-2101$. [CrossRef]

29. Carmel, Y.; Kent, R.; Bar-Massada, A.; Blank, L.; Liberzon, J.; Nezer, O.; Sapir, G.; Federman, R. Trends in ecological research during the last three decades-A systematic review. PLoS ONE 2013, 8, e59813. [CrossRef] [PubMed]

30. Wirta, H.K.; Hebert, P.D.N.; Kaartinen, R.; Prosser, S.W.; Várkonyi, G.; Roslin, T. Complementary molecular information changes our perception of food web structure. Proc. Natl. Acad. Sci. USA 2014, 111, 1885-1890. [CrossRef] [PubMed]

31. Morris, R.J.; Lewis, O.T.; Godfray, H.C.J. Experimental evidence for apparent competition in a tropical forest food web. Nature 2004, 428, 310-313. [CrossRef] [PubMed] 
32. Levins, R. Evolution in Changing Environments; Princeton University Press: Princeton, NJ, USA, 1968.

33. Forsman, A.; Betzholtz, P.E.; Franzén, M. Faster poleward range shifts in moths with more variable colour patterns. Sci. Rep. 2016, 6, 36265. [CrossRef] [PubMed]

34. Rosenblatt, A.E.; Schmitz, O.J. Interactive effects of multiple climate change variables on trophic interactions: A meta-analysis. Clim. Chang. Responses 2014, 1, 1-10. [CrossRef]

35. Forsman, A.; Wennersten, L. Inter-individual variation promotes ecological success of populations and species: Evidence from experimental and comparative studies. Ecography 2016, 39, 630-648. [CrossRef]

36. Gruner, D.S.; Bracken, M.E.S.; Berger, S.A.; Eriksson, B.K.; Gamfeldt, L.; Matthiessen, B.; Moorthi, S.; Sommer, U.; Hillebrand, H. Effects of experimental warming on biodiversity depend on ecosystem type and local species composition. Oikos 2016. [CrossRef]

37. Reichman, O.J.; Jones, M.B.; Schildhauer, M.P. Challenges and opportunities of open data in ecology. Science 2011, 331, 703-705. [CrossRef] [PubMed]

38. Anonymous. Community cleverness required. Nature 2008, 455. [CrossRef]

39. The Tree of Life Web Project. Available online: http://tolweb.org/tree/ (accessed on 30 September 2015).

40. International Union for Conservation of Nature. The IUCN Red List of Threatened Species; Version 2013.2; IUCN: Gland, Switzerland, 2013.

41. International Nucleotide Sequence Database Collaboration. Available online: http://www.insdc.org/ (accessed on 30 September 2015).

42. Perrings, C.; Duraiappah, A.; Larigauderie, A.; Mooney, H.A. The biodiversity and ecosystem services science-policy interface. Science 2011, 331, 1139-1140. [CrossRef] [PubMed]

43. Global Crop Diversity Trust Website. Available online: https://www.croptrust.org/ (accessed on 30 September 2015).

44. Chew, L.L.; Chong, V.C.; Wong, R.C.; Lehette, P.; Ng, C.C.; Loh, K.H. Three decades of sea water abstraction by kapar power plant (Malaysia): What impacts on tropical zooplankton community? Mar. Pollut. Bull. 2015, 101, 69-84. [CrossRef] [PubMed]

45. Bamber, R.N.; Spencer, J.F. The benthos of a coastal power station thermal discharge canal. J. Mar. Biol. Assoc. UK 1984, 64, 603-623. [CrossRef]

46. Lardicci, C.; Rossi, F.; Maltagliati, F. Detection of thermal pollution: Variability of benthic communities at two different spatial scales in an area influenced by a coastal power station. Mar. Pollut. Bull. 1999, 38, 296-303. [CrossRef]

47. Saenger, P.; Stephenson, W.; Moverley, J. Macrobenthos of the cooling watre discharge canal of the Gladstone Power Station, Queensland. Mar. Freshw. Res. 1982, 33, 1083-1095. [CrossRef]

48. Suresh, K.; Ahamed, M.S.; Durairaj, G.; Nair, K.V.K. Impact of power plant heated effluent on the abundance of sedentary organisms, off Kalpakkam, East coast of India. Hydrobiologia 1993, 268, 109-114. [CrossRef]

49. Ehlin, U.; Borenäs, K.; Neuman, E.; Sandström, O. Miljöeffekter Av Stora Kylvattenutsläpp I Ett Varmare Klimat; Elforsk: Stockholm, Sweden, 2012. (In Swedish)

50. Hairston, N.G.J.; van Brunt, R.A.; Kearns, C.M.; Engstrom, D.R. Age and survivorship of diapausing eggs in a sediment egg bank. Ecology 1995, 76, 1706-1711. [CrossRef]

51. Kerfoot, W.C.; Robbins, J.A.; Weider, L.J. A new approach to historical reconstruction: Combining descriptive and experimental paleolimnology. Limnol. Oceanogr. 1999, 44, 1232-1247. [CrossRef]

52. Boyd, P.W. Framing biological responses to a changing ocean. Nat. Clim. Chang. 2013, 3, 530-533. [CrossRef]

53. Merilä, J.; Hoffman, A.A. Evolutionary impacts of climate change. In Oxford Research Encyclopedia of Environmental Science; Oxford University Press: New York, NY, USA, 2016.

54. Forsman, A. Rethinking phenotypic plasticity and its consequences for individuals, populations and species. Heredity 2015, 115, 276-284. [CrossRef] [PubMed]

(C) 2016 by the authors; licensee MDPI, Basel, Switzerland. This article is an open access article distributed under the terms and conditions of the Creative Commons Attribution (CC-BY) license (http://creativecommons.org/licenses/by/4.0/). 